\title{
Comparison between Two Types of Copper Bearing Intrauterine Device Cu375 and Cu380Ag Regarding Bleeding Pattern: (Randomized Controlled Trial)
}

\author{
${ }^{1}$ Mohamed Mahmoud ElSherbieny, ${ }^{1}$ Ahmed Mahmoud Hussein, ${ }^{2}$ Ragaa Galal Rafat Farag \\ ${ }^{1}$ Department of Obstetrics \& Gynecology, Faculty of Medicine, Ain Shams University, ${ }^{2}$ Department of Obstetrics \& \\ Gynecology, Faculty of Medicine, Tanta University
}

\begin{abstract}
Background: The complications of IUDs are abnormal uterine bleeding, dysmenorrhea, expulsion of the IUD or perforation of the uterus. Due to these complications, 5 to 15 percent of women will stop using the IUD during one year. The most common complication of using IUDs is bleeding that is the cause of 15 to 30 percent of the rejection and exclusion of copper IUDs by the users. Except for progesterone IUDs, all IUDs can lead 50-100 percent increase the amount of menstrual blood than before the insertion.

Purpose: To compare between two types of copper IUDs different in shape and size $\mathrm{Cu} 375 \& \mathrm{Cu} 380 \mathrm{Ag}$ regarding bleeding pattern.

Patients and Methods: This is a randomized controlled clinical trial. The study was conducted at Family Planning Outpatient Clinic at Department of Obstetrics \& Gynecology at Ain Shams Maternity Hospital on 220 patients divided into two groups with insignificant differences between two groups as regard age ( $\mathrm{p}$-value $0.934)$.

Results: 110 participants recruited in each group. In group A, drop out after 1month was 6 women and only 70 women had subjective changes in bleeding pattern. After 1year, drop out was 8 women. In group B, drop out after 1 month was 4 women and only 79 women had subjective changes in bleeding pattern. After 1year, drop out was 5 women.

Conclusion: One of the most common complications of IUD users is bleeding. These complications vary in the different types of IUDs. The results of this study showed that the use of the IUD ML CU 375 causes a significant decrease in the rate of bleeding.
\end{abstract}

Keywords: Bleeding Pattern, Copper Bearing, Intention-to-treat

\section{INTRODUCTION}

Copper intrauterine devices are valuable birth control resources ${ }^{(1)}$. Because of the duration of high impact in contraception, low failure rate, reversibility and low cost, copper IUD is used by over 130 million women around the world ${ }^{(2)}$.

The primary mechanism of action of the copper IUD is the prevention of fertilization through a cytotoxic inflammatory reaction that is spermicidal ${ }^{(3)}$. In copper IUD users, the copper concentration in cervical mucus is substantial and leads to an inhibition of sperm motility ${ }^{(4)}$. Because copper ions also result in significant endometrial changes, sperm migration, quality, and viability at the level of the endometrium is hindered. There is also, indirect clinical evidence that the copper IUD has post fertilization contraceptive effects. Placing a copper IUD, even in the early luteal phase, is a highly effective emergency contraceptive ${ }^{(5)}$.

There are two types of commonly used IUDs including the Multi Load CU 375 IUD and Copper T 380A IUD. IUD Copper T $380 \mathrm{~A}$ is a $\mathrm{T}$ shaped framework of polyethylene that contains 380 square millimeters of copper ${ }^{(2)}$. The IUD ML CU 375 is a tree-shaped device that contains 375 square millimeters copper woven around the body.
Some studies showed no differences of effects of the two IUD ML CU 375 and IUD Copper $\mathrm{T}$ 380A types ${ }^{(6)}$. Other studies were conducted have shown that the amount of bleeding in IUD Copper T 380A was further ${ }^{(7)}$.

Another descriptive study showed that bleeding and dysmenorrhea are the most common complications for IUD ML CU 375 and IUD Copper T 380A, so that these two complications in users of IUD ML CU 375 was significantly higher than IUD Copper T 380A group ${ }^{(8)}$.

\section{PATIENTS AND METHODS} clinical trial.

Study design: Randomized controlled

Study setting: The study was conducted at Family Planning Outpatient Clinic at Department of Obstetrics \& Gynecology at Ain Shams Maternity Hospital. The study was approved by the Ethics Board of Ain Shams University and an informed written consent was taken from each participant in the study.

Patients Selection: Participants selected in this study was women seeking a contraceptive method and counceled to use IUD. Participants will be distributed randomly into two groups: Group A: 
including 110 women will use U-Kare ${ }^{\circledR}$ IUD $(\mathrm{Cu}$ 375). Group B: including 110 women will use Silver line ${ }^{\circledR}$ IUD $(\mathrm{Cu} 380 \mathrm{Ag})$.

Method of randomization: Computer generated randomization method was used for randomization.

Inclusion Criteria: Women aged between 20-40 years old. Time of IUD insertion must be post menstrual. IUD was inserted to women who desire to use IUD as contraceptive method.

Exclusion criteria: Irregular menstrual cycle. Congenital anomalies in uterine cavity. Presence of cervical abnormalities or infection. Presence of PID. Uncontrolled diabetes mellitus. Pelvic tuberculosis or genital tract cancer. Past history of ectopic pregnancy. Clinical evidence of anaemia. Previous failure of IUD.

\section{Methods}

All participants in the study were subjected to the following: History: Personal history: Name, age, occupation, residency and special habits. Obstetric history: parity, mode of delivery, number of children. Menstrual history: Duration of the menses, amount of bleeding and number of pads. Past history: of any medical disease.

Examination: General examination to exclude: Pallor, signs of anaemia or jaundice. Obesity. Extreme thinness. Swollen abdomen or edema. Local examination to exclude: Any signs of PID or cervical abnormalities or infection. Pelvic tuberculosis or genital tract tumors.

\section{Insertion of IUD:}

Steps of U-Kare ${ }^{\circledR}$ IUD (Cu 375) insertion: Lay the U-Kare (Cu375) pack on a flat surface. Strip the wrapping from the device by lifting the transparent sheet of the pack from the end marked open. The vertical stem of the device is already preloaded in the insertion tube. The side arms do not require loading into the tube. They are sufficiently flexible to adapt to the shape of cervical canal. Pick up the insertion tube (with pre-loaded IUD) grasping the tube at indentation near its distal end and move the flange to the distance corresponding to the sound length in $\mathrm{cm}$. Lift the insertion tube (with pre-loaded IUD) from its pack. Carefully insert the U-Kare (Cu375) into the uterus until it touches the fundus and the flange rests against the external os while maintaining the steady downward traction with the tenaculum to straighten the uterus axis. No attempt should be made to force insertion. When U-Kare touch the fundus, it is released into the uterine cavity by simply withdrawing the insertion tube. Trim the threads of the U-Kare (Cu375) to 3-4 cm measured from the external OS.

Steps of Silver line® IUD (Cu380Ag) insertion: Ensure Vertical arm of frame is fully inside the insertion tube and the opposite end of the insertion tube should be closer to the package bottom seal. Place the package on a clean, hard, flat surface. Partially open the plastic covering till half way to the yellow flange. However, IUD and insertion tube are not to be withdrawn. While holding the tube firmly with one hand, release the threads from flange and draw the device into the insertion tube by grasping both the threads and gently pulling the device into the insertion tube until the knobs at the ends of horizontal arm cover the opening of the tube. Steadying the flange with one hand, pull the insertion tube until the lower edge of the flange indicates the measure obtained with the uterine sound, on the scale printed on insertion tube. Holding the package with open end up, and the flaps away from each other. Holding the threads slightly stretched with one hand, put the solid rod into the insertion tube to almost touch the bottom of pulled frame. The silver line $\mathrm{Cu} 380 \mathrm{Ag}$ is now ready for insertion. Gently introduce the loaded insertion assembly through the cervical canal and advance upward until flange comes into contact with cervical OS. Ensure that the flange is in the horizontal plane. Holding the solid rod stationary by one hand withdraw the insertion tube by your free hand to touch ribbed part of solid rod thereby the flange is removed from cervical OS as well (approx $1.5 \mathrm{~cm}$ ). The arms of frame are now unfolded. Advance the insertion tube until the flanqe is touching the cervical OS again. The Silver line $\mathrm{Cu} 380 \mathrm{Ag}$ is now in contact with fundus. To release the device entirely from the insertion tube, hold the solid rod firmly and draw the tube back' as far as the backstop. First, gently withdraw the solid rod (hold the insertion tube stationary while removing the solid rod) and then the insertion tube from the cervical canal to prevent pulling the device from the fundal position. Cut the threads so that they are visible only 3-4 cm outside the cervix.

\section{Follow up:}

Post-Insertion Follow-Up Visit will be: Firstly, after one month or after the first post insertion menses to assess any bleeding changes through menstrual history (duration of bleeding, amount of bleeding and numbers of pads) and any prominent offensive vaginal discharge accompanied by fever or 
chills through questionnaire we conducted for all participants.

Statistical Methods: Data were analyzed using IBM $\odot$ SPSS $\odot$ Statistics version 23 (IBM $\odot$ Corp., Armonk, NY, USA).

Ethics: The study was approved from the Ethical Committee of the Department of Obstetrics and Gynecology, Faculty of Medicine, Ain Shams University. Informed written consent was taken from all participants before recruitment in the study and after explaining the purpose of the study.

\section{RESULTS}

This randomized controlled clinical trial conducted at Family Planning Outpatient Clinic on 220 patients divided into two groups with following result:

Table (1): Demographic characteristics in both study groups

\begin{tabular}{|l|c|c|c|c|c|}
\hline \multirow{2}{*}{ Variable } & \multicolumn{2}{|c|}{$\begin{array}{c}\text { Cu375) Group A } \\
(\mathbf{n}=110)\end{array}$} & \multicolumn{2}{|c|}{$\begin{array}{c}\text { Cu380Ag) Group } \\
\text { B (n=110) }\end{array}$} & \multirow{2}{*}{ p-value* } \\
\cline { 2 - 5 } & Mean & SD & Mean & SD & \\
\hline $\begin{array}{l}\text { Age } \\
\text { (years) }\end{array}$ & 28.8 & 5.4 & 28.8 & 6.0 & 0.934 \\
\hline
\end{tabular}

This table showed that there was insignificant difference between the two groups as regard age ( $p$-value 0.934).

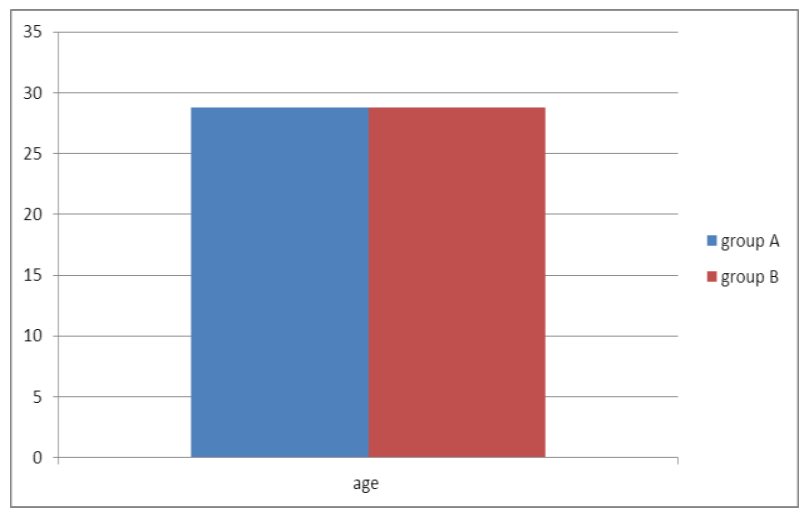

Figure (1): Comparison between two groups as regard age.

110 participants recruited in each group. In group (A), drop out after 1month was 6 women and only 70 women had subjective changes in bleeding pattern. After 1year, drop out was 8 women. In group (B), drop out after 1month was 4 women and only 79 women had subjective changes in bleeding pattern. After 1year, drop out was 5 women.
Table (2): Duration of menses in both study groups

\begin{tabular}{|c|c|c|c|c|c|c|c|c|}
\hline \multirow{2}{*}{\multicolumn{2}{|c|}{$\begin{array}{r}\text { Variable } \\
\text { Time } \\
\end{array}$}} & \multicolumn{3}{|c|}{$\begin{array}{l}\text { (Cu375) } \\
\text { Group A }\end{array}$} & \multicolumn{3}{|c|}{$\begin{array}{c}\text { (Cu380Ag) } \\
\text { Group B }\end{array}$} & \multirow[b]{2}{*}{$\begin{array}{c}\text { p- } \\
\text { value* }\end{array}$} \\
\hline & & $\mathrm{n}$ & $\begin{array}{c}\text { Mea } \\
n\end{array}$ & $\begin{array}{l}\text { S } \\
\text { D }\end{array}$ & $\mathrm{n}$ & $\begin{array}{c}\text { Mea } \\
n\end{array}$ & $\begin{array}{l}\text { S } \\
\text { D }\end{array}$ & \\
\hline \multirow{3}{*}{$\begin{array}{c}\text { Durati } \\
\text { on of } \\
\text { menses } \\
\text { (days) }\end{array}$} & $\begin{array}{l}\text { Pre- } \\
\text { inserti } \\
\text { on } \\
\end{array}$ & $\begin{array}{c}11 \\
0\end{array}$ & 4.5 & $\begin{array}{l}0 . \\
7\end{array}$ & $\begin{array}{c}11 \\
0\end{array}$ & 4.7 & $\begin{array}{l}0 . \\
7\end{array}$ & 0.168 \\
\hline & $\begin{array}{l}1 \\
\text { month } \\
\text { post- } \\
\text { inserti } \\
\text { on } \\
\end{array}$ & 70 & 6.1 & $\begin{array}{l}0 . \\
7\end{array}$ & 79 & 6.9 & $\begin{array}{l}0 . \\
9\end{array}$ & $<0.001$ \\
\hline & $\begin{array}{l}12 \\
\text { month } \\
\text { s post- } \\
\text { inserti } \\
\text { on }\end{array}$ & 62 & 5.9 & $\begin{array}{l}0 . \\
6\end{array}$ & 74 & 6.6 & $\begin{array}{l}0 . \\
8\end{array}$ & $<0.001$ \\
\hline
\end{tabular}

This table showed that there was insignificant difference between two groups as regard duration of menses pre insertion of device (p-value 0.168). While, after 1 month and 12 months group $\mathrm{B}$ had higher duration period with significant differences ( $\mathrm{p}$-value $<0.001$ ).

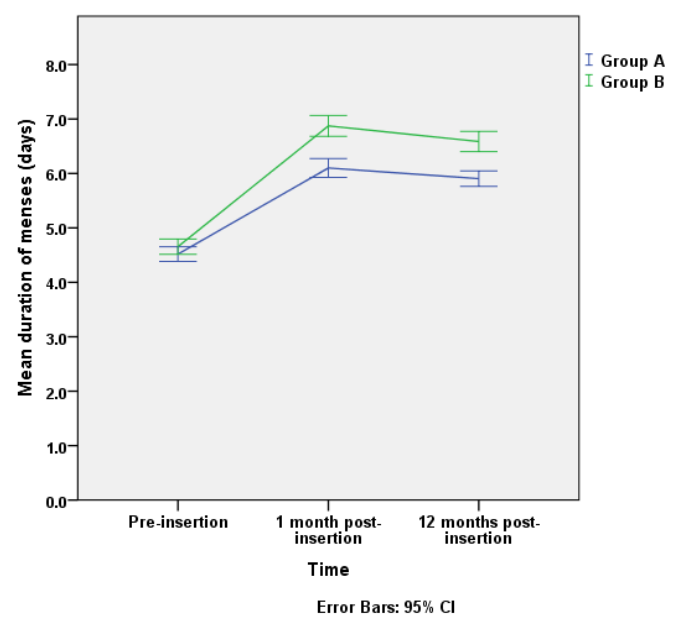

Figure (2): Mean duration of menses in both study groups. Error bars represent the $95 \%$ confidence interval (95\% CI).

Table (3): Number of pads in both study groups

\begin{tabular}{|c|c|c|c|c|c|c|c|c|}
\hline \multicolumn{2}{|c|}{ Variable } & \multicolumn{3}{|c|}{$\begin{array}{l}(\mathrm{Cu} 375) \\
\text { Group A }\end{array}$} & \multicolumn{3}{|c|}{$\begin{array}{c}\text { (Cu380Ag) } \\
\text { Group B }\end{array}$} & \multirow[b]{2}{*}{ p-value* } \\
\hline Time & & $\mathrm{n}$ & Mean & SD & $\mathrm{n}$ & Mean & SD & \\
\hline \multirow{3}{*}{$\begin{array}{l}\text { Number } \\
\text { of pads }\end{array}$} & Pre- insertion & 110 & 8.3 & 1.7 & 110 & 8.8 & 1.9 & 0.019 \\
\hline & $\begin{array}{l}1 \text { month post- } \\
\text { insertion }\end{array}$ & 70 & 11.6 & 1.6 & 79 & 12.5 & 1.6 & 0.001 \\
\hline & \begin{tabular}{|l|}
12 months \\
post-insertion
\end{tabular} & 62 & 10.2 & 1.0 & 74 & 11.8 & 1.5 & $<0.001$ \\
\hline
\end{tabular}

This table showed that there was significant difference between the two groups as regard number of pads either pre insertion, 1 month and 12 months post-insertion with higher number of pads in group (B). 


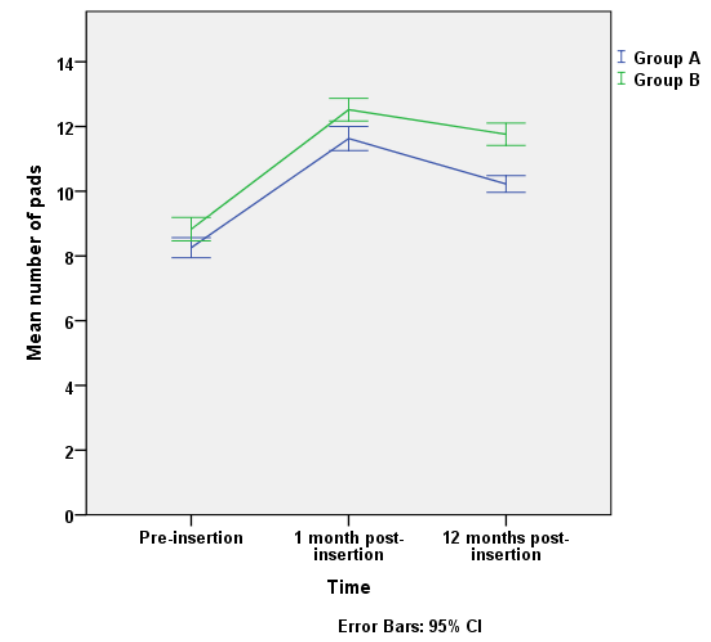

Figure (3): Mean number of pads in both study groups. Error bars represent the $95 \%$ confidence interval (95\% CI).

Table (4): Change in menses duration after IUD insertion in both study groups

\begin{tabular}{|l|l|c|c|c|c|c|c|c|}
\hline \multicolumn{1}{|c|}{ Variable } & \multicolumn{3}{c|}{$\begin{array}{c}\text { Cu375) } \\
\text { Group A }\end{array}$} & \multicolumn{3}{c|}{$\begin{array}{c}\text { (Cu380Ag) } \\
\text { Group B }\end{array}$} & \multirow{2}{*}{ p-value* } \\
\hline Time post-insertion & $\mathrm{n}$ & Mean & SD & n & Mean & SD & \\
\hline $\begin{array}{l}\text { Increase } \\
\text { in menses } \\
\text { duration } \\
\text { (\% of } \\
\text { pre- } \\
\text { insertion } \\
\text { value) }\end{array}$ & 1 month & 70 & 45.9 & 18.8 & 79 & 55.1 & 19.4 & $\mathbf{0 . 0 0 4}$ \\
\cline { 2 - 7 } & 12 months & 62 & 40.8 & 14.8 & 74 & 49.2 & 15.0 & $\mathbf{0 . 0 0 1}$ \\
\hline
\end{tabular}

This table showed that as regard changes in menses duration in comparison with pre insertion duration there was significant increase in duration between two groups with higher increase in duration in group (B) after 1 month and after 12 months.

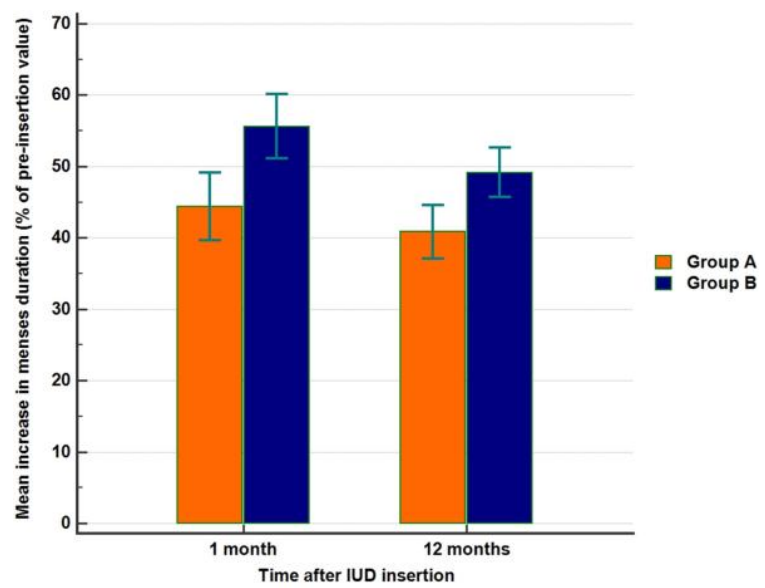

Figure (4): Mean change in menses duration in both study groups. Error bars represent the $95 \%$ confidence interval $(95 \% \mathrm{CI})$.
Table (5): Change in pads' number after IUD insertion in both study groups

\begin{tabular}{|c|c|c|c|c|c|c|c|c|}
\hline \multirow{2}{*}{\multicolumn{2}{|c|}{$\begin{array}{c}\text { Variable } \\
\text { Time post-insertion }\end{array}$}} & \multicolumn{3}{|c|}{$\begin{array}{l}\text { (Cu375) } \\
\text { Group A }\end{array}$} & \multicolumn{3}{|c|}{$\begin{array}{c}\text { (Cu380Ag) } \\
\text { Group B }\end{array}$} & \multirow{3}{*}{$\begin{array}{r}\text { p-value* } \\
0.876 \\
\end{array}$} \\
\hline & & $\mathrm{n}$ & Mean & SD & $\mathrm{n}$ & Mean & SD & \\
\hline \multirow{2}{*}{$\begin{array}{l}\text { Increase in } \\
\text { pads } \\
\text { number (\% } \\
\text { of pre- } \\
\text { insertion } \\
\text { value) }\end{array}$} & 1 month & 70 & 56.21 & 23.62 & 79 & 55.51 & 30.09 & \\
\hline & 12 months & 62 & 37.94 & 19.36 & 74 & 46.79 & 28.60 & $\mathbf{0 . 0 3 3}$ \\
\hline
\end{tabular}

This table showed that as regard change in percentage of pads number in comparison to pre insertion number there was statistically insignificant differences between the two groups after 1month but after 12 month group (B) had higher number than group (A) in comparison with preinsertion number.

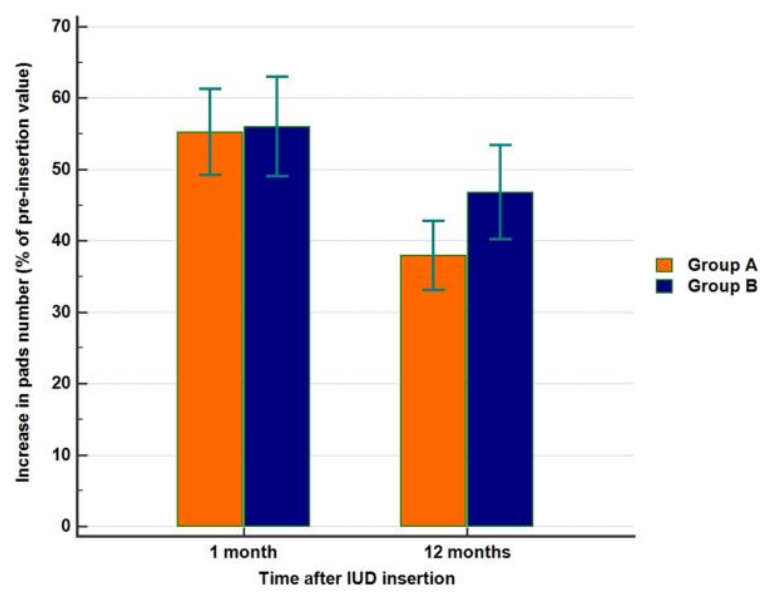

Figure (5): Mean change in pads number in both study groups. Error bars represent the $95 \%$ confidence interval (95\% CI).

Table (6): Per-protocol (PP) assessment at 1 month

\begin{tabular}{|c|c|c|c|c|c|}
\hline \multirow[t]{2}{*}{ Variable } & \multicolumn{2}{|c|}{$\begin{array}{c}(\text { Cu3757) } \\
\text { Group A } \\
(\mathrm{n}=104)\end{array}$} & \multicolumn{2}{|c|}{$\begin{array}{c}\text { (Cu380Ag) } \\
\text { Group B } \\
(\mathbf{n}=106)\end{array}$} & \multirow[t]{2}{*}{$\begin{array}{c}\text { p- } \\
\text { value* }\end{array}$} \\
\hline & $\mathrm{n}$ & $\%$ & $\mathrm{n}$ & $\%$ & \\
\hline $\begin{array}{l}\text { Subjective change of } \\
\text { menses at } 1 \text { month }\end{array}$ & 70 & $67.3 \%$ & 79 & $74.5 \%$ & 0.288 \\
\hline $\begin{array}{l}\text { Fever / copious } \\
\text { offensive vaginal } \\
\text { discharge } \\
\text { at } 1 \text { month }\end{array}$ & 0 & $0.0 \%$ & 0 & $0.0 \%$ & $\mathrm{n} / \mathrm{a}$ \\
\hline
\end{tabular}

This table showed that by Per-protocol (PP) assessment at 1 month there was insignificant subjective change of menses at 1 month in two groups. 


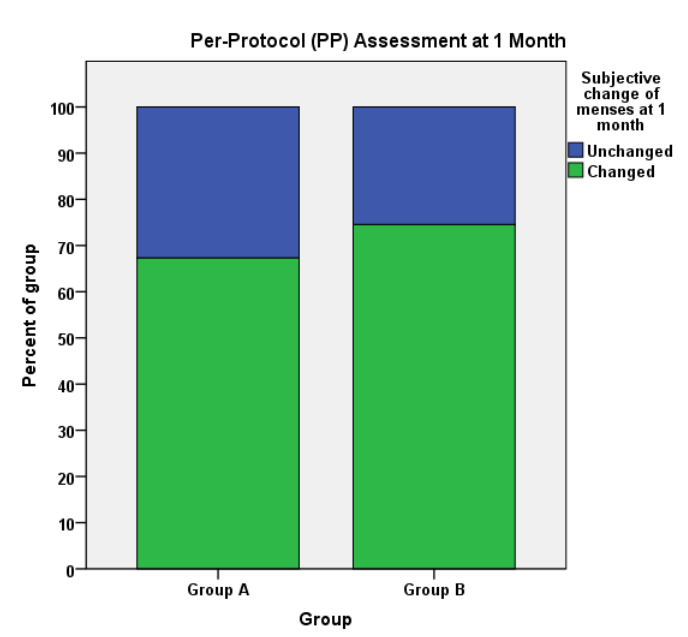

Figure (6): Per-protocol (PP) assessment of the change in menses at 1 month.

Table (7): Per-protocol (PP) assessment at 12 month.

\begin{tabular}{|c|c|c|c|c|c|}
\hline \multirow[t]{2}{*}{ Variable } & \multicolumn{2}{|c|}{$\begin{array}{c}(\text { Cu375) } \\
\text { Group A } \\
(n=96 \\
\end{array}$} & \multicolumn{2}{|c|}{$\begin{array}{c}\text { (Cu380Ag) } \\
\text { Group B } \\
(n=101)\end{array}$} & \multirow[t]{2}{*}{ p-value* } \\
\hline & $\mathbf{n}$ & $\%$ & 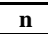 & $\%$ & \\
\hline Inter-menstrual bleeding & 21 & $21.9 \%$ & 37 & $36.6 \%$ & 0.029 \\
\hline $\begin{array}{l}\text { Abnormal vaginal } \\
\text { discharge }\end{array}$ & 42 & $43.8 \%$ & 48 & $47.5 \%$ & 0.668 \\
\hline Thread felt & 78 & $81.3 \%$ & 78 & $77.2 \%$ & 0.599 \\
\hline Plastic part felt & 1 & $1.0 \%$ & 2 & $2.0 \%$ & 1.000 \\
\hline Satisfied with IUD & 94 & $97.9 \%$ & 92 & $91.1 \%$ & 0.059 \\
\hline \multicolumn{6}{|l|}{ Reason for dissatisfaction } \\
\hline Spotting & $1 / 2$ & $50.0 \%$ & $9 / 9$ & $100.0 \%$ & 0.182 \\
\hline Infection & $1 / 2$ & $50.0 \%$ & $5 / 9$ & $55.6 \%$ & 1.000 \\
\hline Bleeding & $0 / 2$ & $0.0 \%$ & $4 / 9$ & $44.4 \%$ & 0.491 \\
\hline
\end{tabular}

This table showed that by Per-protocol (PP) assessment at 12 month inter menstrual bleeding after 12 months was the only significant action between two groups as it was higher in group (B) with p-value (0.029).

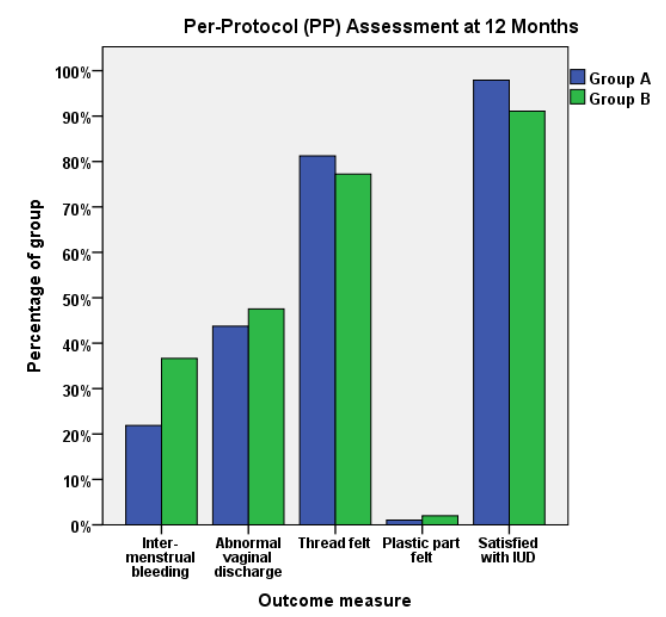

Figure (7): Per-protocol (PP) assessment of the main outcome measures at 12 months.
Table (8): Intention-to-treat (ITT) assessment at 1 month

\begin{tabular}{|l|c|c|c|c|c|}
\hline \multirow{2}{*}{ Variable } & \multicolumn{2}{|c|}{$\begin{array}{c}\text { (Cu375) } \\
\text { Group A } \\
(\mathbf{n}=110)\end{array}$} & \multicolumn{2}{|c|}{$\begin{array}{c}\text { (Cu380Ag) } \\
\text { Group B } \\
(\mathbf{n}=110)\end{array}$} & \multirow{2}{*}{ p-value* } \\
\cline { 2 - 5 } & $\mathrm{n}$ & \% & $\mathrm{n}$ & \% & \\
\hline $\begin{array}{l}\text { Change of menses at 1 } \\
\text { month }\end{array}$ & 70 & $63.6 \%$ & 79 & $71.8 \%$ & 0.249 \\
\hline $\begin{array}{l}\text { Fever / copious } \\
\text { offensive vaginal } \\
\text { discharge at 1 month }\end{array}$ & 0 & $0.0 \%$ & 0 & $0.0 \%$ & $\mathrm{n} / \mathrm{a}$ \\
\hline
\end{tabular}

This table showed that intention-to-treat (ITT) assessment at 1 month as regard change in menses was insignificant between the two groups (p-value 0.249).

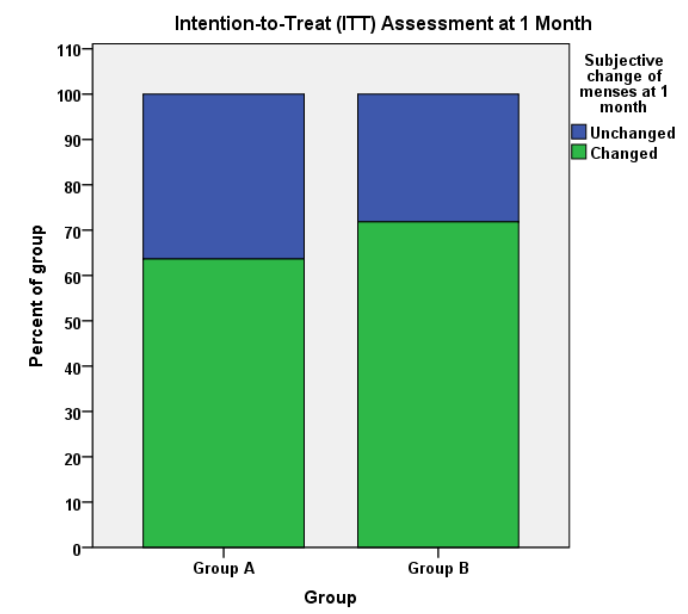

Figure (8): Intention-to-treat (ITT) assessment of the change in menses at 1 month.

Table (9): Intention-to-treat (ITT) assessment at 12 month.

\begin{tabular}{|l|c|c|c|c|c|}
\hline \multirow{2}{*}{ Variable } & \multicolumn{2}{|c|}{$\begin{array}{c}\text { (Cu375) } \\
\text { Group A } \\
(\mathbf{n = 1 1 0})\end{array}$} & \multicolumn{2}{c|}{$\begin{array}{c}\text { (Cu380Ag) } \\
\text { Group B } \\
(\mathbf{n = 1 1 0})\end{array}$} & \multirow{2}{*}{ p-value* } \\
\cline { 2 - 5 } & $\mathbf{n}$ & $\mathbf{\%}$ & $\mathbf{n}$ & $\%$ & \\
\hline $\begin{array}{l}\text { Inter-menstrual } \\
\text { bleeding }\end{array}$ & 21 & $19.1 \%$ & 37 & $33.6 \%$ & $\mathbf{0 . 0 2 1}$ \\
\hline $\begin{array}{l}\text { Abnormal vaginal } \\
\text { discharge }\end{array}$ & 42 & $38.2 \%$ & 48 & $43.6 \%$ & 0.493 \\
\hline Thread felt & 78 & $70.9 \%$ & 78 & $70.9 \%$ & 1.000 \\
\hline Plastic part felt & 1 & $0.9 \%$ & 2 & $1.8 \%$ & 1.000 \\
\hline Satisfied with IUD & 94 & $85.5 \%$ & 92 & $83.6 \%$ & 0.852 \\
\hline $\begin{array}{l}\text { Reason for } \\
\text { dissatisfaction }\end{array}$ & & & & & \\
\hline \multicolumn{1}{|c|}{ Spotting } & $1 / 16$ & $6.3 \%$ & $9 / 18$ & $50.0 \%$ & 0.008 \\
\hline Infection & $1 / 16$ & $6.3 \%$ & $5 / 18$ & $27.8 \%$ & 0.180 \\
\hline Bleeding & $0 / 16$ & $0.0 \%$ & $4 / 18$ & $22.2 \%$ & 0.105 \\
\hline
\end{tabular}

This table showed that by ITT assessment at 12 month the intermenstrual bleeding and reason for dissatisfaction spotting was significantly higher 
in group (B) than group (A) with p-value (0.021), $(0.008)$ respectively.

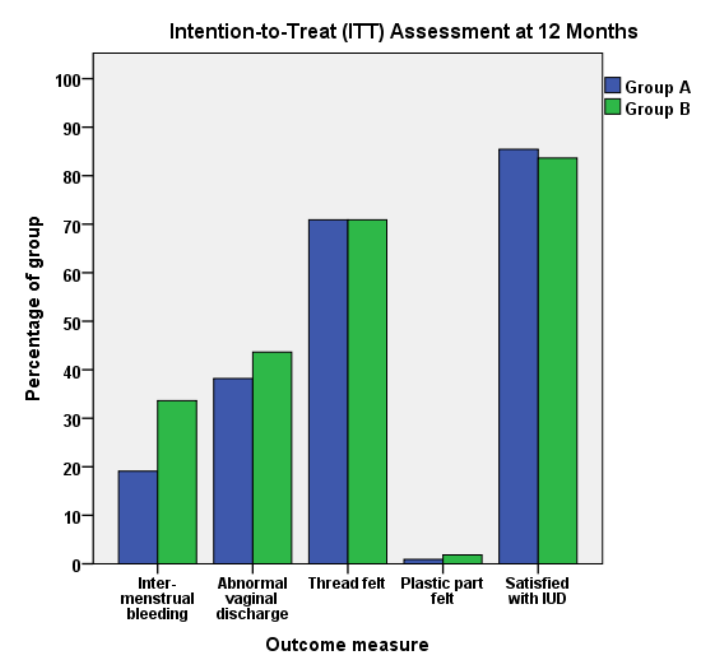

Figure (9): Intention-to-treat (ITT) assessment of the main outcome measures at 12 months.

\section{DISCUSSION}

Copper Intrauterine devices are the most widely used method of long-acting reversible contraception (LARC) with a very low failure of $0.2-1.0 \%{ }^{(9)}$.

In the present study we aimed to compare between two types of copper IUDs different in shape and size, Cu375 \& $\mathrm{Cu} 380 \mathrm{Ag}$, regarding bleeding pattern. Our randomized controlled clinical trial was conducted at Family Planning Outpatient Clinic on 220 patients divided into two groups.

\section{Findings and interpretation}

In the present study, we found that there was insignificant difference between the two groups as regard age ( $p$-value 0.934). There were insignificant differences between the two groups as regard duration of menses pre insertion of device (p-value 0.168$)$ but after 1 month and 12 months, group "B" $(\mathrm{Cu} 380 \mathrm{Ag})$ had higher duration period with significant differences ( $p$-value $<0.001)$.

There were significant differences between the two groups as regard number of pads at 1 month and 12 months post- insertion with higher number of pads in group "B" $(\mathrm{Cu} 380 \mathrm{Ag})$.

In the present study, we found also that at 1 month and 12 months post-insertion, group "B"
$(\mathrm{Cu} 380 \mathrm{Ag})$ had higher duration period and higher number of pads with significant differences $(p$ value $<0.001$ ).

In addition, we found that Per-protocol (PP) assessment at 1 month showed insignificant subjective change of menses at 1 month in the two groups. Per-protocol (PP) assessment at 12 month inter menstrual bleeding after 12 months was the only significant action between the two groups as it was higher in group " $\mathrm{B}$ " $(\mathrm{Cu} 380 \mathrm{Ag})$ with $\mathrm{p}$-value 0.029. Intention-to-treat (ITT) assessment at 1 month as regard change in menses was insignificant between the two groups (p-value 0.249 ).

As regards the intention-to-treat (ITT) assessment at 12 month, the intermenstrual bleeding and reason for dissatisfaction, spotting was significantly higher in group "B" $(\mathrm{Cu} 380 \mathrm{Ag})$ than group "A" (Cu375) with p-value (0.021) and (0.008) respectively.

\section{Strengths and weaknesses of the study}

This study comprised a large number of participants $(220$ women $)$ but the statistically calculated sample size was (60 women) and this increased the strength of the study.

The main weakness of the study was that it needed to be multicenter study. Also, follow up only for 1 year not 5 year (duration of usage of IUD). Similarity and Differences in results and
conclusions in relation to other studies

In agreement with our result Shahnazi et al. (10) study include 48 married women in reproductive age (15-48 years old) divided into two groups, 24 in IUD ML CU 375 and 24 in IUD Copper T 380A group. Both groups were matched in demographic and pregnancy characteristics with no statistically significant differences $(\mathrm{P}>0.05)$. The data collection lasted nine months. The result of this study showed that the use of IUD ML CU 375 significantly decreased the mean bleeding in the study participants and IUD Copper T 380A significantly increased it. In the fourth month, in the IUD ML CU 375 users the scores of bleeding severity decreased by as much as $39 \%$, but in IUD Copper T 380A users it increased to $86 \%^{(10)}$.

Roberto-Flores and others ${ }^{(11)}$ found, in their 3-year study in a multicenter clinical trial by UK Family Planning and Reproductive Health 
Research Network, that bleeding following early postpartum IUD insertion is more intense with the $\mathrm{Cu}$ T380 IUD than with the Multiload 375 IUD.

In Kumar et al. ${ }^{(12)}$ study where 300 women included in the study divided into two groups. Mean age of the study population was $24.99 \pm 4.2$ years. The study showed that in group "A" $12 \%(\mathrm{n}=18)$ women and in group " $\mathrm{B}$ " $14 \%$ $(\mathrm{n}=21)$ subjects complained of post insertion bleeding/spotting per vaginum at 1 month of IUCD insertion ${ }^{(12)}$. Menorrhagia was reported by $7.33 \%$ $(\mathrm{n}=11)$ subjects in group "A" and $8.66 \%(\mathrm{n}=13)$ subjects in group " $\mathrm{B}$ " at the end of 1 year follow up. This difference was not statistically significant $(\mathrm{P}>0.05)^{(12)}$.

On statistical analysis, the difference in level of satisfaction with IUCD use was statistically significant $(p=0.001)$ by Fisher's Exact test. Adverse effects were more in CuT380A than $\mathrm{Cu} 375$ in first 6 month of insertion but at 1 year overall adverse effects were low and comparable in both groups. However, the degree of satisfaction was high in $\mathrm{Cu} 375$ as the side effects were less in this group in first 6 month of insertion and this was comparable to our study ${ }^{(12)}$.

Moreover, Khan et al. ${ }^{(13)}$ in their study on 150 women attended the Family Planning Clinic during the 16 months period in which the study was carried out. Out of these, 80 women were selected for IUCD insertion, 40 were selected for multiload and 40 for Copper-T. Insertion was performed on healthy sexually active women who had requested contraception and had no contraindication for the fitting of an IUCD. All the participants who were selected for IUCD insertion had copper-T 380 and $\mathrm{Cu} 375$ IUCD was used during study. The peak age range for the IUCD insertion was 26-38 years old. No patient was aged less than 20 years ${ }^{(13)}$. They showed that main problems noted were menorrhagia $(5 \%)$ in patients using $\mathrm{Cu} 375 \mathrm{IUCD}$ compared to $2 \%$ in Copper-T users $^{(13)}$.

El Beltagy et al. ${ }^{(14)}$ study, which enrolled 300 recently normally delivered females (within 48 h). The women were counseled for post partum use of an IUD as a pre-discharge family planning method. This study is in contrary to our result, where it showed that at 6 weeks, the Cu T380 IUD menstruating users were more complaining of menorrhagia and metrorrhagia than the multiload
375 IUD menstruating users. However, at 6 months, the bleeding abnormalities were higher among the Multiload 375 IUD menstruating users than the $\mathrm{Cu}$ T380 IUD menstruating users. This finding might indicate that the large size and spikes of the multiload IUD made it fit well in the large uterine cavity during the early post partum period. However, it might when involution of the uterus occurs by 6 months after delivery, the large surface area of the multiload IUD causes more menorrhagia and metrorrhagia ${ }^{(14)}$.

\section{Relevance of the findings and implications for clinical practice}

The results of the above studies showed that in group "B", which used silver line ${ }^{\circledR}$ IUD (Cu380Ag), there was significant increase in duration and number of pads used during menses.

Possible cause of differences in bleeding rates in both IUDs could be related to the amount of copper and increase in contact. That by increased amount of copper in the contact area, the amount of bleeding would be increased ${ }^{(15)}$.

The only possible draw back of IUCD could be that overall majority of included women were already anaemic and IUCD increased the menstrual blood loss by about 40-50\%. Severe menstrual blood loss had been reported to occur in first three months after the insertion and then declined in the rest of the years ${ }^{(16)}$.

\section{Disclosure statement}

The authors declare that there was no conflict of interest associated with this manuscript.

\section{Funding}

This study received no financial support.

\section{CONCLUSION}

One of the most common complications of IUD users is bleeding and these complications vary in the different types of IUDs. The results of this study showed that the use of the IUD ML CU 375 caused a significant decrease in the rate of bleeding.

\section{REFERENCES}
1. Hubacher D, Ricalde RL, Taylor JD et al. (2001): Use of copper intrauterine devices and the risk of tubal infertility among nulligravid women. $\mathrm{N}$ Engl $\mathrm{J}$ Med., 345(8): 561-567.


2. Berek J, Berek S (2011): Novak's Gynecology $15^{\text {th }}$ ed. Philadelphia: Lippincott Williams \& Wilkins. Available at: https://www.amazon.com/BerekNovaks-Gynecology- Jonathan-MMS/ $\mathrm{dp} / 1451114338$

3. Holland MK, White IG (1988): Heavy metals and human spermatozoa. III. The toxicity of copper ions for spermatozoa. Contraception, 38: 685-695.

4. Stanford JB, Mikolajczyk RT (2002): Mechanisms of action of intrauterine devices: update and estimation of postfertilization effects. Am J Obstet Gynecol., 187: 1699-1708.

5. Cheng L, Gulmezoglu AM, Piaggio G et al. (2008): Interventions for emergency contraception. https:// www. ncbi. nlm. nih. gov/ pubmed/22895920

6. O'Brien PA, Kulier R, Helmerhorst FM et al. (2008): Copper-containing framed intrauterine devices for contraception: a systematic review of randomized controlled trials. Contraception, 77(5): 318-327.

7. Ogendengbe $\mathrm{OK}$, Giwa OO, Adeniran BA (1991): A comparison of multiload with copper T IUD in Lagos. Br J Fam Plann., 17(4): 67-69.

8. Afkari B, Iranfar S, Abasi $P$ et al. (2002): Evaluation of Multi-Load 375 and T Cu 380A IUD complications in women referred to the health and treatment settings of Kermanshah University of Medical Sciences in 2000. Arak Medical University Journal, 5(3): 42-47.

9. Winner B, Peipert JF, Zhao $Q$ et al. (2012): Effectiveness of long acting reversible contraception. N Engl J Med., 366(21): 1998-2007.

10. Shahnazi M, Sarrafi S, AsgariJafarabadi M et al. (2014): Comparing Hemorrhages and Dysmenorrhea with Copper T380A and Multiload 375 Intrauterine Devices: A Randomized Clinical Trial. Journal of Caring Sciences, 3(3): 193-204.
11. Roberto-Flores, Guerrero-Carreno FJ, Vazquez-Estrada LA (2003): A comparative randomized study of three Mexican women. Cont., 67: 273-6.

12. Kumar M, Kumar M, Aggarwal $P$ et al. (2017): A study to evaluate and compare the expulsion and continuation rates of post placental insertion of $\mathrm{Cu} 375$ and CuT 380A in Indian women at a premier hospital in New Delhi, India. Int J Reprod Contracept Obstet Gynecol., 6(9): 39924000.

13. Khan SA, Amin ZU, Jadoon $S$ et al. (2010): A Comparative trial of copper $T$ 380 and $\mathrm{Cu} 375$ IUCD. J Ayub Med Coll Abbottabad., 22(3): 185-187.

14. El Beltagy NS, Darwish EA, Kasem MS et al. (2011): Comparison between Cupper T380 IUD and Multiload 375 IUD in early post partum insertion. Middle East Fertility Society Journal, 16: 143-148.

15. Higham JM, O'brien PM, Shaw $R$ (1990): Assessment of menstrual blood loss using a pictorial chart. BJOG: An International Journal of Obstetrics \& Gynaecology, 97(8): 734-739.

16. Anwar M, Widayanto S, Maruo T et al. (1993): Return of fertility after the removal of intrauterine devices: a comparison of inert and copper bearing devices. Asia Oceania J Obstet Gynaecol., 19(1): 77-83. 